\title{
Ni-BASED CW6MC: EFFECT OF THE INTERNAL REVERT RECYCLE ON THE SOUNDNESS OF THE ALLOY
}

\author{
Andrea Gruttadauria $\mathbb{\infty}$, Silvia Barella, and Anna Guerra \\ Mechanical Department, Politecnico Di Milano, Milano, Italy
}

Copyright $(\subset) 2021$ The Author(s)

https://doi.org/10.1007/s40962-021-00600-z

\begin{abstract}
The CW6MC alloy is a nickel-based alloy used to withstand acidic environments, especially in the oil and gas industry where it is used in the production of valves, impellers, and pipes. This alloy is the foundry counterpart of the best known A625 for plastic deformation. Regarding nickel-based alloys, a scrap market like that in the case of steel has not yet been established, therefore, especially in

accordance with the technical specifications and analysed to evaluate the effect of scrap on the final chemical composition, the microstructure, the mechanical properties and corrosion resistance. Following the analyses carried out, it was determined that the amount of acceptable scrap content (of those analysed) without compromising the material properties corresponds to $30 \%$.
\end{abstract} the case of foundries, scrap generally comes from internal recycling (casting waste, feeders, sprues, runners, etc.) to be certain of the origin and quality of the material. In this work, four castings with different percentage of recycled content $(0 \%, 30 \%, 70 \%, 100 \%)$ were produced in
Keywords: CW6MC, alloy A625, nickel-based alloy, nickel foundry, homescrap, virgin alloy, revert

\section{Background}

Ni-based alloys can be defined as alloys that have extraordinary properties (strength, temperature and corrosion resistance) appropriate for applications where corrosion resistance and thermal stability play a central role. In this scenario, the CW6MC alloy is a cast nickel-based corrosion resistant alloy developed to withstand aggressive environments. Given the excellent corrosion resistance properties in sour-gas conditions, the oil and gas industry is greedy for this alloy. The CW6MC alloy has even been used in other fields such as phosphoric acid production. In this case, fluorine, chloride and silica compounds present in the manufacturing process are dangerous from a corrosion point of view, and CW6MC is able to withstand such critical environments. This alloy represents the cast counterpart of wrought superalloy Inconel 625. CW6MC and nickel-based alloys are largely employed nowadays, and the use of metallic materials in general has been subjected to a huge increase in recent centuries. Humans

Received: 04 February 2021 / Accepted: 18 March 2021 /

Published online: 13 April 2021 continuously need to extract, process and produce metals to sustain the demands of technology. But metals stocks are changing over time: in the past centuries, a significant amount of available reserves were to be found in the Earth's crust, but now these stocks are running out. Thus, an expensive and added value material such as CW6MC alloy must be highlighted. If industries are able to exploit metal recycling, even in the case of these complex alloys, the circular economy concept might be applied in a smart way. Thus, costs saving might be possible and the environmental impact might be reduced ${ }^{1-4}$.

Given that metals are important recyclable resources, recycling provides the freedom to reuse metals. Recycling can contribute to sustainability and to controlling the demands of technology.

Furthermore, efficiently recycling nickel-based alloys is still challenging. The nickel-based alloy market is not as well consolidated as in case of steel and more than anything, it is difficult to find reliable suppliers that sell highquality 625 scrap, without any grade modification. It is a fact that most cast components have less than $30 \%$ of the 
original weight of alloy melted. The remaining $>70 \%$ accounts for remelt stock preparation, runner and feeder metal scrap, machining waste, etc., which is known as "revert" alloy. To save costs of raw materials and energy, companies invest in revert alloys, although virgin alloys provide more benefits in terms of mechanical properties and soundness ${ }^{5-9}$. Indeed, the final properties of the casting strictly depend on the quality of supplied charge material: the amount of revert alloy, that is added to the production process, can affect the quality and properties of resulting material $^{10}$.

Anyway, as nickel industries grow, they are looking for the perfect element combinations to guarantee better performance of the final product. Thus, control of the final chemical composition and performance must be obtained in case of revert alloys as well. In the case of CW6MC alloy and nickel-based alloys, this management is challenging to achieve. But there are a lot of early investigations and studies which examine their effective industrial employment. These studies explain that the concentration of major elements in revert alloys is nearly the same. Thus, one expects that they will not modify the alloy's properties. In contrast, secondary elements such as nitrogen and oxygen change slightly and affect the alloy's behaviour. Thus, this study analyses the revert addition effect on the performance of cast CW6MC alloy, investigating the changes in chemical composition, alloy microstructure, mechanical properties and defects. Understanding the revert addition's influence is the key point for improving functioning of the casting process and obtaining the revert product with the best performance.

\section{Material and Methodology}

The ingots were provided by Fondinox S.p.a., an Italian foundry specialized in nickel-based alloy and stainless steel.

CW6MC (30x50x200 mm) ingots were obtained by sand casting with the chemical composition, according to ASTM A494/A494M ${ }^{11}$, listed in table 1 . The ingots were casted in silica casting sand following the normal foundry practice.

Three ingots per scrap amount were cast in the same mould at a pouring temperature of around $1470^{\circ} \mathrm{C}$. The

Table 1. CW6MC Chemical Composition (\%wt.) According to ASTM A494/494M

\begin{tabular}{llllllll}
\hline $\mathrm{Ni}$ & $\mathrm{Cr}$ & $\mathrm{Mo}$ & $\mathrm{Nb}$ & $\mathrm{Fe}$ & $\mathrm{C}$ & $\mathrm{Mn}$ & $\mathrm{Si}$ \\
\hline Bal. & $20-23$ & $8-10$ & $3.15-4.5$ & $\max$ & $\max$ & $\max$ & $\max$ \\
& & & & 5 & 0.06 & 1 & 1 \\
\hline
\end{tabular}

Solidification and cooling of the ingots occurred in the mould and they were removed after 24 hours. The sketch and a photo of an ingot are reported in Figure 1.

The amount of scrap was chosen according to the common market requirement; the four amounts of scrap were $0 \%$ (virgin alloy), 30\%, $70 \%$ and $100 \%$ (full revert). The chemical composition was obtained by analysis, and three measurements for each ingot were taken at different cross sections. The scrap used was exclusively home scrap of the foundry (feeders and runners), this allowed to be sure about the provenience of the material, its soundness and its purity. The scrap, before using as metal charge, was cleaned by sandblasting (using AISI304 stainless steel as blasting particles), and the chemical composition was verified by quantometer analysis. The melting of the material and the mixing with the virgin counterpart followed the normal foundry praxis with no special adjustments. No gas flux was used, neither for refining, nor for oxidation protection.

One of the three ingots was solution annealed (SA) for 4 hours at $1200^{\circ} \mathrm{C}$ and water quenched. The annealing solution's parameters were chosen according to the practice applied at the foundry that cast the alloy: with these parameters, the chemical composition and microstructure were certainly homogenised by eliminating chemical gradients due to segregation.

The macrostructure and microstructure were analysed using optical microscopy (OM) and scanning electron microscopy (SEM) after sample preparation. The macrostructure of the material was obtained after cutting the samples and grinding the surfaces by sandpaper (180 grit); the microstructure was obtained after grinding (2500 grit) and polishing ( $1 \mu \mathrm{m}$ diamond paste) the surfaces. In both cases, the surfaces were cleaned in ethanol by ultrasound. The macro-etching was been done using a solution of $95 \% \mathrm{HCl}$ and $5 \% \mathrm{H}_{2} \mathrm{O}_{2}{ }^{12}$. For the micro-etching, a solution of $20 \% \mathrm{HNO}_{3}$ and $60 \% \mathrm{HCl}^{13}$ was used. In both cases, the time of applying the solution to the samples varied around 1 minute depending on the sample's response. SEM is equipped with EDS (energy dispersive spectroscopy) and BSE (backscatter electron) probes to detect the chemical composition.

Secondary dendritic arm spacing (sDAS) and defect percentage were measured using Image $\mathrm{J}$ software.

Tensile tests were performed in accordance with ASTM E8/E8M-16a (Specimen 3) ${ }^{14}$. These tests were carried out at room temperature applying a cross-head speed of $2 \mathrm{~mm} /$ min, and Charpy V-notch tests were carried out according to ASTM E23 ${ }^{15}$. Three repetitions for each condition were performed. 

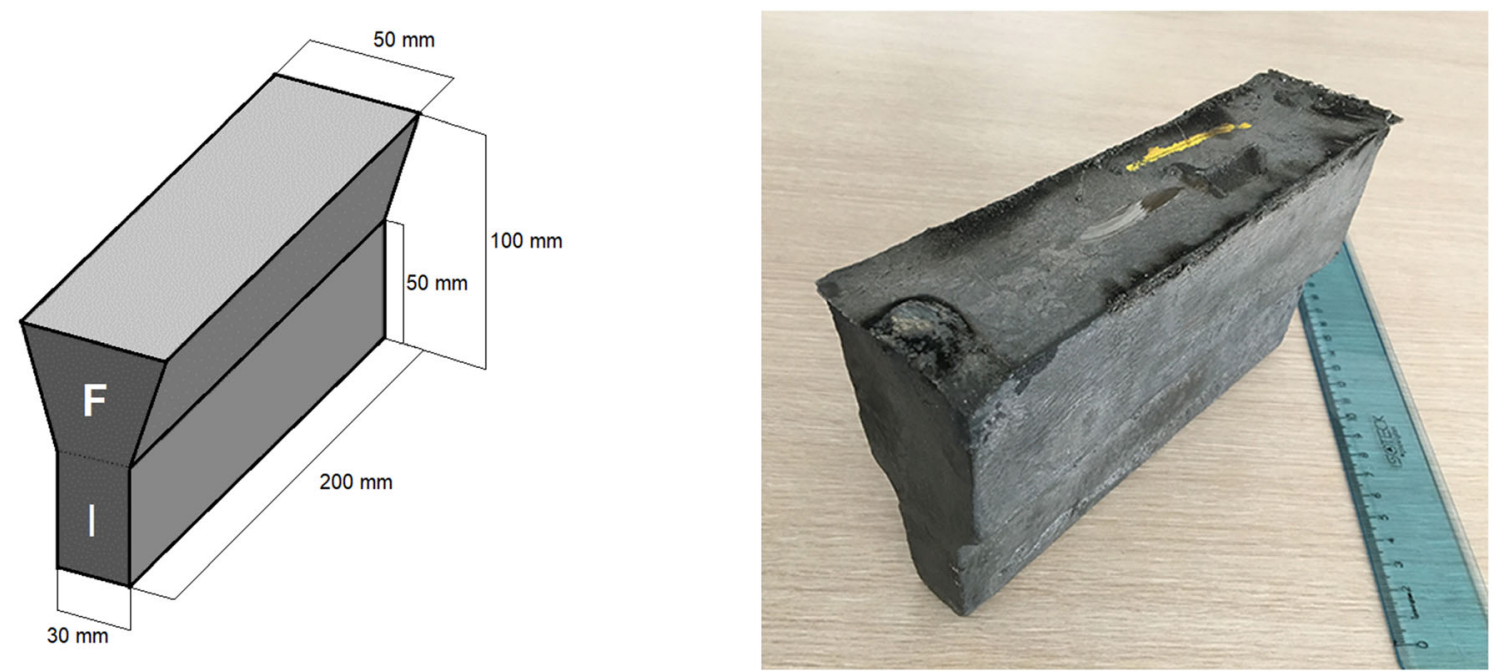

Figure 1. Sketch and photo of an ingot casted by Fondinox S.p.a: "F" feeder and "I" ingot

The material's response to localized corrosion in oxidizing chloride environments after solubilization was measured according to ASTM G48-11 (Method A) ${ }^{16}$. All samples were polished with a 120-grit abrasive paper, and the weights and total exposed area were computed before the test began. Specimens were immersed in the test solution (100g of ferric chloride $\mathrm{FeCl}_{3}: 6 \mathrm{H}_{2} \mathrm{O}$ and $900 \mathrm{~mL}$ reagent water) at room temperature for 72 hours at $23^{\circ} \mathrm{C}$. At the end of the period, the samples were removed from the solution and cleaned to remove corrosion products from deep pits. The samples were also weighted at the end of the test to evaluate their weight loss.

\section{Result and Discussion}

The ingots' chemical composition changes in relation to the amount of scrap. These changes show a continuous trend that is not due to normal foundry practice. Figure 2 indicates the concentration of $\mathrm{Ti}, \mathrm{Al}, \mathrm{S}$ and $\mathrm{P}$.

The amount of $\mathrm{Ti}$ and $\mathrm{Al}$ does not vary significantly when the scrap content is increased, but a slight decrease occurs.

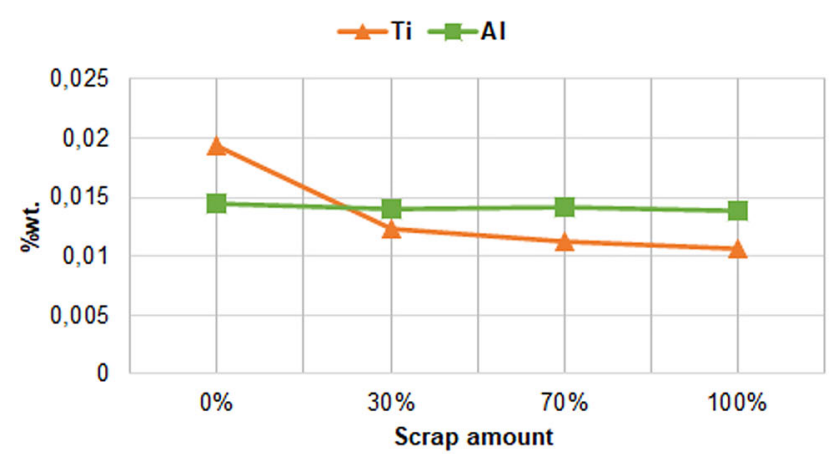

(a)
In foundries, $\mathrm{Al}$ and $\mathrm{Ti}$ are only used in very small amounts to perform de-oxidation of pure $\mathrm{Ni}$. The slight decrease can be explained by considering that the virgin melts need to be totally deoxidised, while the other castings present more scrap content that has been deoxidised. Thus, a smaller addition of $\mathrm{Al}$ and $\mathrm{Ti}$ is necessary for revert melting ${ }^{17}$.

The same trend, but more accentuated, is recorded for $\mathrm{S}$ and P. Alloying elements are necessary to achieve the correct final chemical composition and these elements are not pure but present traces of polluting elements such as $\mathrm{S}$ and $\mathrm{P}$. When the amount of the scrap is increased, with a balanced composition, a further amount of alloying element is not necessary, thus the $\mathrm{S}$ and $\mathrm{P}$ amounts decrease. A decrease in these elements is positive for the mechanical response since they increase brittleness ${ }^{7}$.

As shown in Figure 3, the Fe and $\mathrm{Si}$ contents increase in relation to the amount of scrap, while $\mathrm{Nb}$ remains constant. Since scrap is not purified before the re-melts, it is only cleaned with steel powder (AISI 304), and a residual amount of Fe powder or sand casting can be inserted in the melt. Thus, Fe and Si contents are expected to be higher as

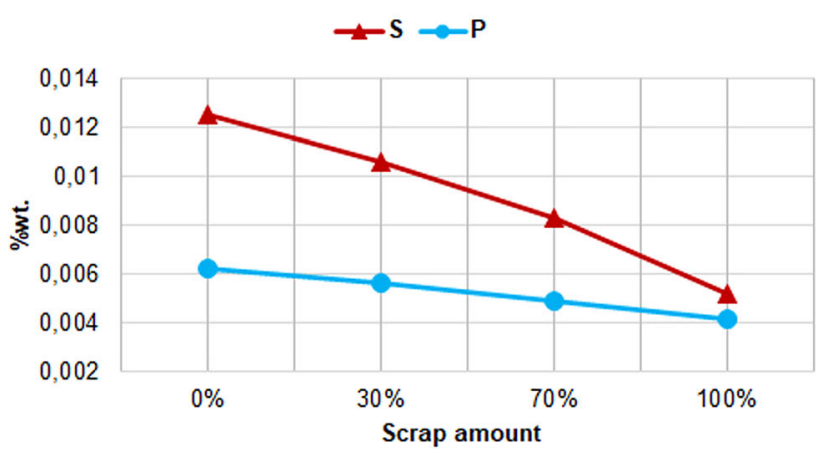

(b)

Figure 2. $T i, A l(a), S$ and $P$ (b) variation in relation to scrap addition 


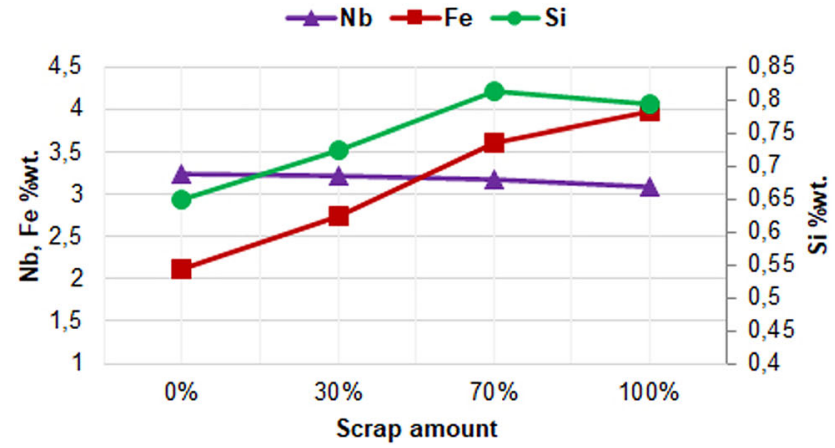

(a)

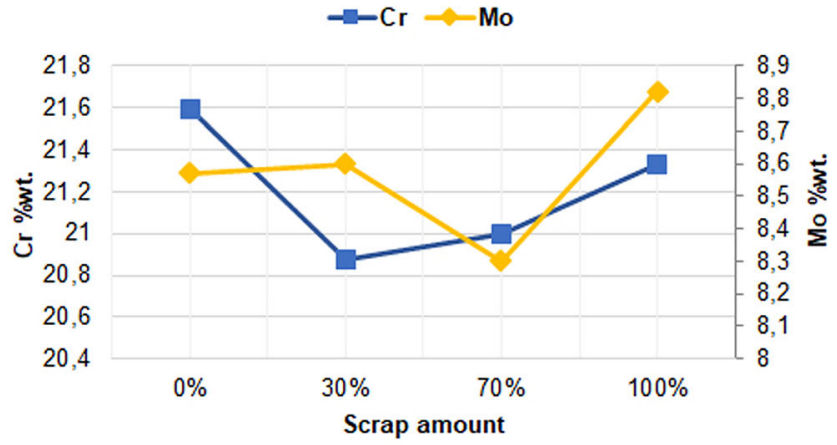

(b)

Figure 3. Main alloying element variation in relation to scrap addition

the amount of recycling increases. Fe promotes the formation of Laves phases and Si promotes their stability, thus an increase in Laves could be responsible for the reduction in mechanical properties ${ }^{18,19}$. Cr has a strong tendency to oxidate, so the remelting process promotes the formation of chromium oxides leading to a loss of chromium in the alloy and an increase in oxides in the matrix. Indeed, $\mathrm{Cr}$ decreases with the amount of scrap because of remelting losses. Due to this evidence, it was necessary to add $\mathrm{Cr}$ to the melt for $70 \%$ and $100 \%$ of the scrap, in order to achieve the composition required by ASTM A494/494M. Finally, Mo amounts fluctuate as normal in a foundry process ${ }^{3,20}$.

Not only do $\mathrm{Cr}$ and Mo increase the mechanical properties by solid solution strengthening, but they are also essential for corrosion resistance: $\mathrm{Cr}$ is fundamental for the formation of the passive film, while Mo stabilizes this oxide. Moreover, Mo is also responsible for the formation of the Laves phases ${ }^{1,21}$.

As indicated in Figure 4, $\mathrm{C}$ and $\mathrm{N}$ increase with the amount of scrap. The increase in $\mathrm{C}$ content is related to cover powders used in melt protection that remain incorporated into the feeder or to the release agent incorporated into the cast surface. The $\mathrm{N}$ increase in the ingot and feeder can be justified considering that with $0 \%$ scrap content (virgin alloy) the overall amount of $\mathrm{N}$ is entrapped from the air. In case of recycled ingots, a part of the $\mathrm{N}$ is already entrapped in the pre-melted scrap, and the addition of further virgin melts introduces more $\mathrm{N}$. The presence of nitrogen and carbon leads to the formation of nitrides and carbonitrides, which cause brittleness in the alloy. Anyway, the variation of the amount of $\mathrm{C}$ is slight, but also a small increase in $\mathrm{C}$ can increase the solidification temperature range and change the alloy's hot cracking behaviour. The amount of $\mathrm{C}$ is one of the main parameters responsible for the formation of carbides, and the $\mathrm{C} / \mathrm{Nb}$ ratio indication for Laves phase formation: when the ratio is increased, the Laves phase presence decreases in favour of carbides. Thus, a loss in mechanical and tensile properties is expected when the amount of scrap is increased. Actually, not only Laves phases can be detrimental, but also non-homogeneously distributed carbides ${ }^{22-24}$.

The concentrations of major elements in recycled alloys change respect of those of the virgin alloy; external contaminations increase the amount of $\mathrm{Fe}$ and $\mathrm{Si}$, remelting loss causes the decrease in $\mathrm{Cr}$ and no influence is registered looking at $\mathrm{Nb}$ and Mo that fluctuated (in the range provided by the standard) as common in the foundry process. Moreover, the concentrations of minor elements such as $\mathrm{Ti}$, $\mathrm{Al}, \mathrm{S}$, and $\mathrm{P}$ decreased as a result of a minor use of deoxidants and alloying elements to get the virgin alloy. In

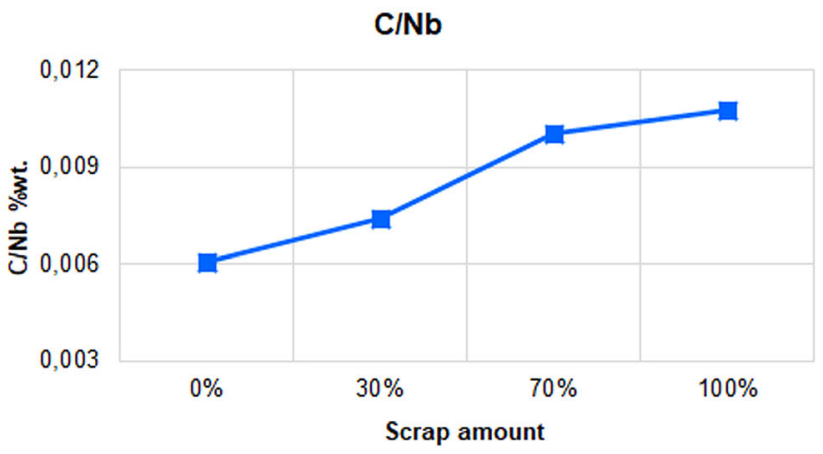

(b)

Figure 4. $\mathbf{C}$ and $\mathbf{N}$ variation in relation to scrap addition 
the end, the increase in $\mathrm{C}$ and $\mathrm{N}$ content could significantly affect the mechanical properties ${ }^{25,26}$.

The four samples mainly present a columnar grain structure caused by competitive growth and aligned with the heat flow. Samples at $0 \%, 30 \%$ and $70 \%$ exhibit coarser grain structures than a $100 \%$ sample. Samples at $0 \%, 30 \%$ and $70 \%$ even show a clear finer grain structure on left side. This difference between left and right grain structure could be related to the location of the sample during cooling. Thus, regions on the left in Figure 4 show finer grain structures than those on the right. Samples at $70 \%$ and $100 \%$ exhibit smaller equiaxed grains on the feeder skin. This phenomenon could be not only related to heat transfer efficiency during cooling, but also to additional elements in these specific samples that act as grain inoculants. A typical example is $\mathrm{N}$, which is a grain refiner. The feeder of the $100 \%$ sample shows a more marked "skin effect": surface grains are smaller than those at the core probably due to $\mathrm{N}$ effect, which tends to be accumulated in the feeding systems and refines grains ${ }^{24,27}$. Figure 5 illustrates the macrostructure of the samples.

Obviously, the casting process is subject to a certain degree of randomness: there are a lot of parameters that influence grain size and shape. Thus, the microstructures observed do not depend mainly on revert addition, but on their position in the mould, the dimensions of the specific mould (all the moulds are similar but not perfectly equal), heat exchange conditions, etc.

Figure 6 shows a more detailed image of the grains; it is possible to appreciate the different crystal domains featuring the dendritic pattern.

Microstructural analysis of as-cast samples shows the typical dendritic structure. $\gamma$ dendrites are visible as the lighter regions, primary and secondary dendritic arms are present. In the overall cases, significant segregation is present. In these zones, elements segregate outside the $\gamma$ dendrites' core and they form secondary phases such as
Laves phases, carbides, nitrides and carbonitrides (Figure 7) 28,29 .

The total average grain size was evaluated for each ingot. This value was measured as the number of grains per unit length, considering the cross section of the ingots. sDAS was investigated to understand how solidification affects the alloy's behaviour. The number of grains per unit length and the secondary dendritic arm spacing (sDAS) are shown in Table 2.

The grain dimension does not vary with the amount of scrap, and the same trend is recorded for the sDAS. The differences, in terms of the standard deviation, are negligible: the heat exchange guides the solidification pattern instead of the chemical composition.

Microstructure analysis of as-cast and solution-annealed samples was performed to determine the main secondary phases present in segregations. The alloy also exhibits secondary phases: carbides, Laves phases, oxides and nitrides. Carbides are in intragranular regions and are mainly NbC primary carbides; they also show traces of Mo or Cr. Carbides show globular and Chinese script (elongated shape) morphologies. $\mathrm{NbC}$ are found to also be in the form of small carbides trails. Laves phases are present in the eutectic Laves-matrix structures and in the form of elongated shaped particles. Their typical formula is $(\mathrm{Cr}, \mathrm{Fe}, \mathrm{Ni})_{2}(\mathrm{Si}, \mathrm{Ti}, \mathrm{Nb}, \mathrm{Mo})$ and they are rich in $\mathrm{Nb}^{18,19,21,22,29}$.

The typical as-cast microstructure of CW6MC alloy and its secondary phases are given in Figure 8; the chemical composition of the compounds is given in Table 3 .

All the ingots were characterized by the same structural constituent, and no differences in typology, dimension or chemical composition were highlighted.

As the carbide nucleates at nitride nuclei in revert alloy, the increase in $\mathrm{N}$ amount measured in the revert lets to an

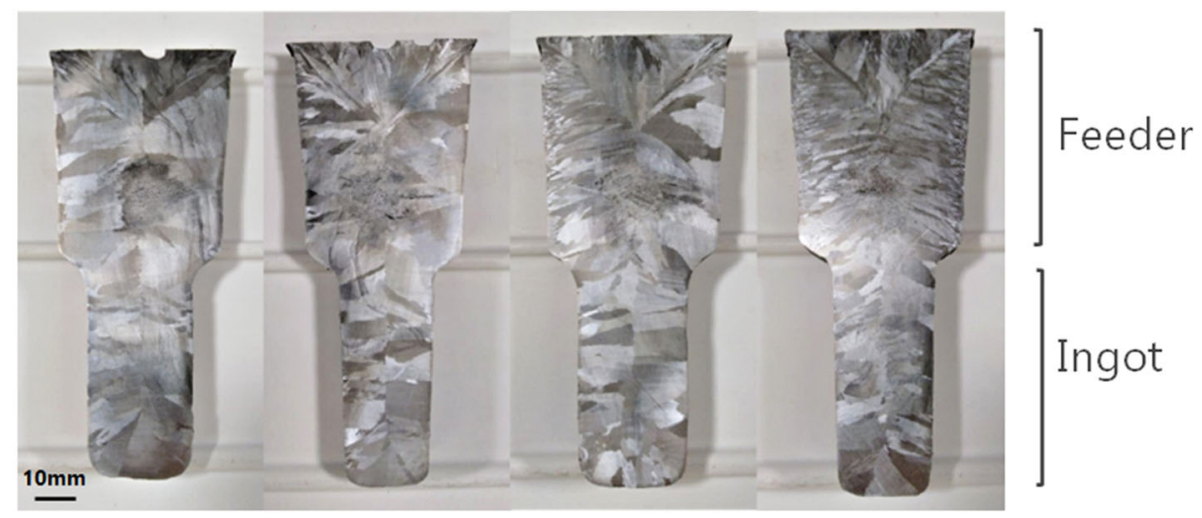

Figure 5. Macro-etching of the cross section of the ingots; the upper part is the feeder. From the left, $0 \%, 30 \%, 70 \%$ and $100 \%$ amount of scrap 


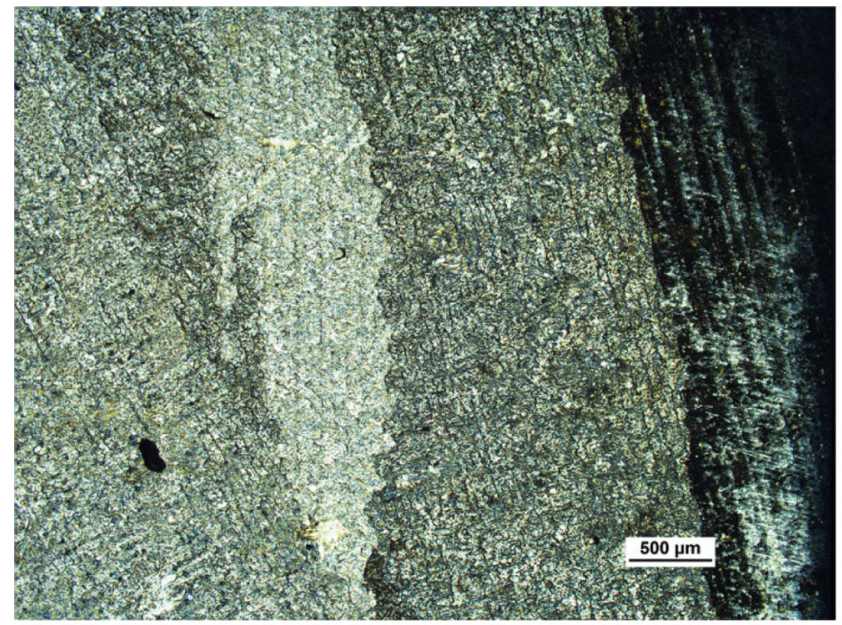

$0 \%$ (Virgin alloy)

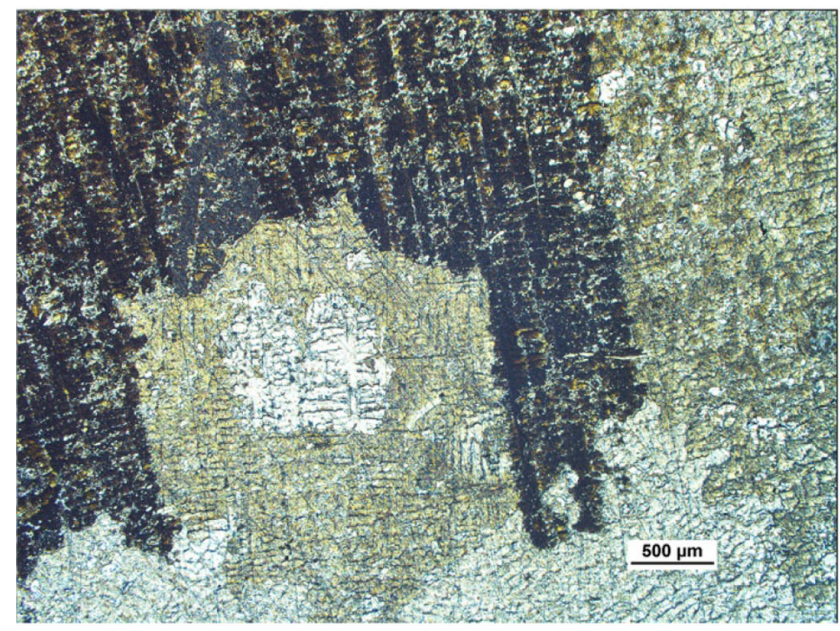

$70 \%$

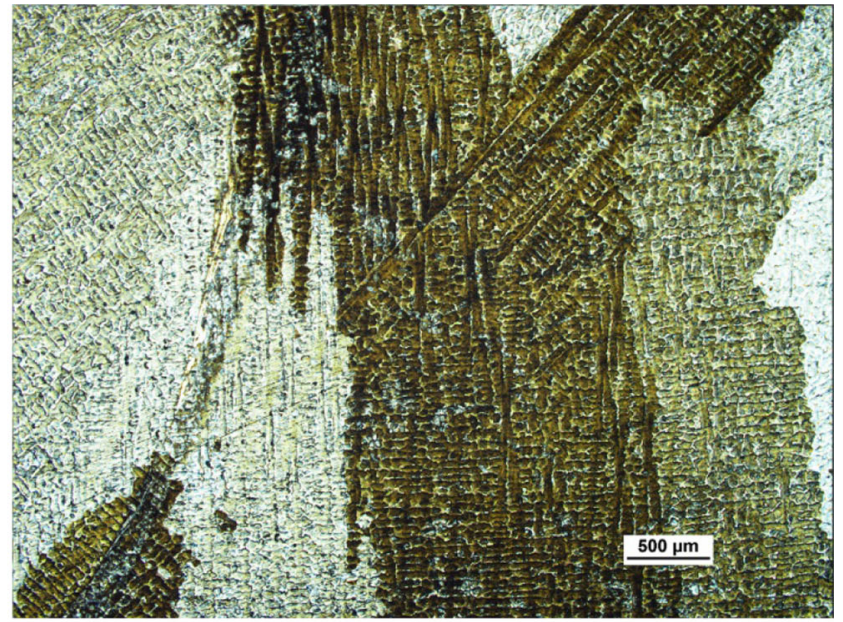

$30 \%$

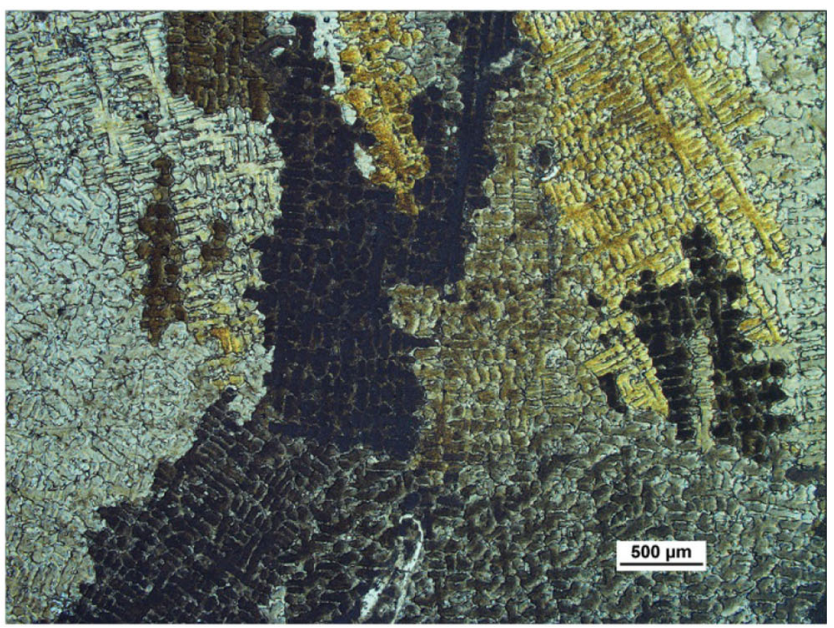

$100 \%$ (Full revert)

Figure 6. Macro-etching of the cross section of the ingots

increase in carbides with also an influence on their morphology. Thereby, the changes in the morphology carbide might be related also to the various carbon concentrations ${ }^{30,31}$.

The ingots showed a different distribution and amount of secondary phases. Figure 9 shows the microstructure in the as-cast condition and after solubilization.

The amount of secondary phases increases with the amount of scrap. These phases form an interdendritic network in the ingots characterized by $70 \%$ and $100 \%$ of scrap. The increase in the number of secondary phases resembles the trend of chemical composition, which shows an increase in segregating elements responsible for the formation of the secondary phases $(\mathrm{C}, \mathrm{Fe}, \mathrm{Si})$. This results in a reduction in mechanical properties. After solubilization, there is a partial reabsorption of the secondary phases network and a rounding of lamellar and eutectic constituents ${ }^{4,18,19}$.
The effect of scrap addition on oxides and porosity formation was investigated. Oxides come from the oxidation of the melt due to casting operations and arise from the scrap (mainly feeders) that is added. If these oxides cannot float and are not removed from the melt, they remain trapped in the metal matrix. Porosities are mainly due to solidification shrinkage and trapped gas $^{32}$. Figure 10 illustrates Cr-oxides and shrinkage porosity. Oxides are mainly mixed $\mathrm{Cr}$ and $\mathrm{Mn}$ oxides and they are recognisable by their square shape and black colour.

Figure 11 shows the trend of the extent of the defect area measured as the sum of the oxide and porosity area.

The amount of defects increases with the amount of scrap added. Therefore, the oxides in the scrap content are added to those formed during casting. Furthermore, the concentration of segregating elements increases with the scrap content. The result is the enrichment of solute in the interdendritic zone accompanied by shrinkage during solidification. Moreover, the blocky carbides and oxides 


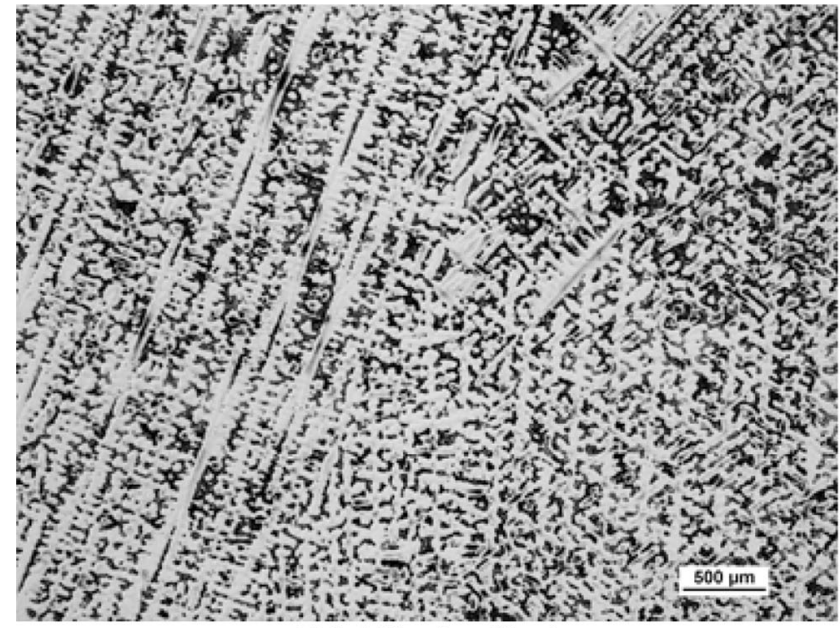

$0 \%$ (Virgin alloy)

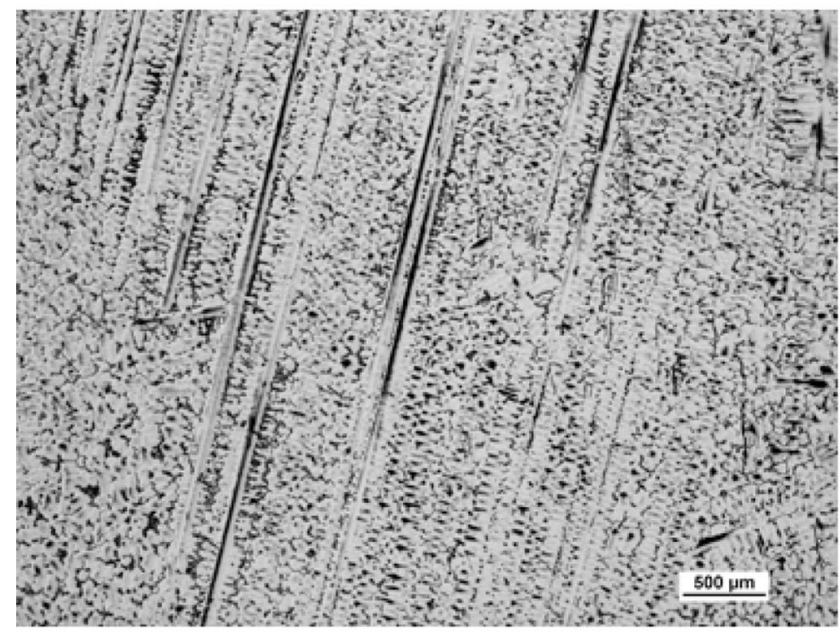

$70 \%$
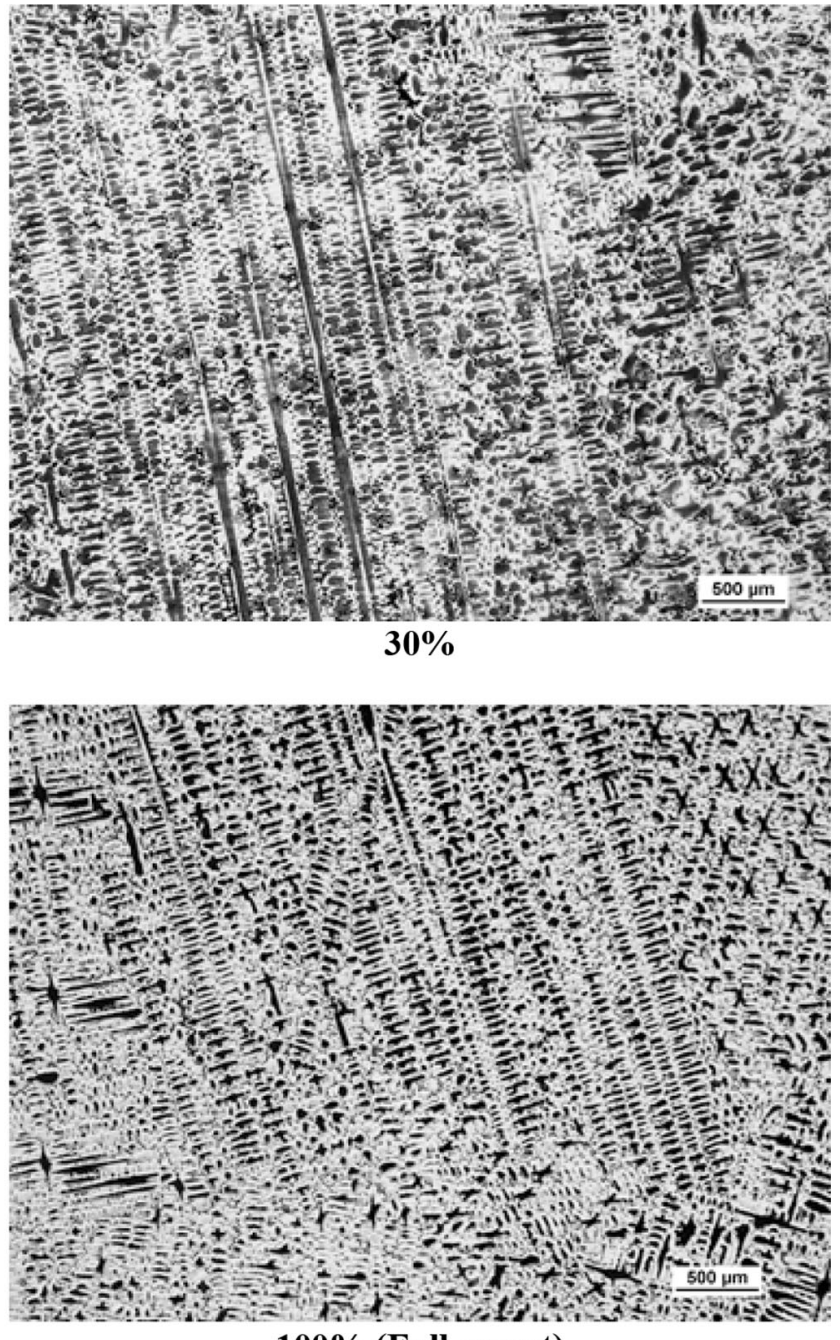

$100 \%$ (Full revert)

Figure 7. Micro-etching of the cross section of the ingots

Table 2. Number of Grains Per Length and sDAS for Different Amounts of Scrap

\begin{tabular}{lllll}
\hline & $0 \%$ & $30 \%$ & $70 \%$ & $100 \%$ \\
\hline Number of grains/length $\left[\mathrm{mm}^{-1}\right]$ & $0.48 \pm 0.09$ & $0.43 \pm 0.11$ & $0.42 \pm 0.13$ & $0.50 \pm 0.08$ \\
sDAS $[\mu \mathrm{m}]$ & $48.05 \pm 7$ & $49.6 \pm 7$ & $55.5 \pm 10$ & $48.7 \pm 6.5$ \\
\hline
\end{tabular}

can clog the dendrite channels leading to a lack of filling of the interdentrditic zones. Furthermore, increasing level of $\mathrm{N}$ demonstrate air entrapment that leads to reduced ductility and that get porosity. It can be seen that the percentage of defects (including porosity and non-metallic inclusions) increases gradually with the addition of the recycled alloy. That will be related to the loose in mechanical properties ${ }^{17,31}$.

Given that oxides and porosity are not affected by thermal treatment, there are no differences between the as-cast and solubilized conditions.
Tensile test and Charpy V-notch tests results are given in Figure 12.

Considering the microstructural analysis, a significant reduction in tensile and mechanical properties is expected when the amount of scrap is increased ${ }^{19,21}$. Indeed, $R_{m}$ tends to decrease as the amount of scrap increases. The lower values associated with both $70 \%$ and $100 \%$ percent scrap are probably due to the presence of secondary phase network in the interdendritic regions. Heat treatment promotes the reabsorption of secondary phases making their networks less continuous ${ }^{33}$. Thus, $\mathrm{R}_{\mathrm{m}}$ tends to increase. After heat treatment, all the ingots reach the minimum 


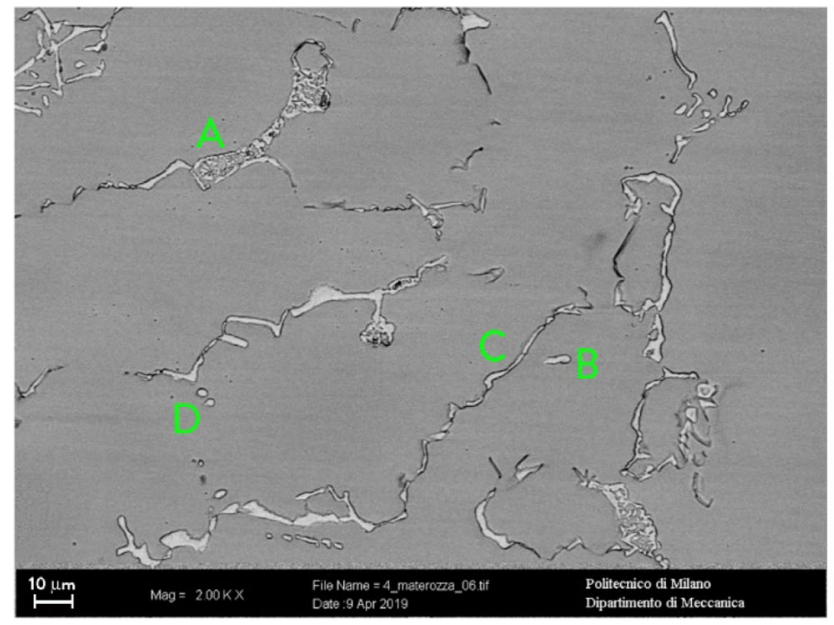

(a)

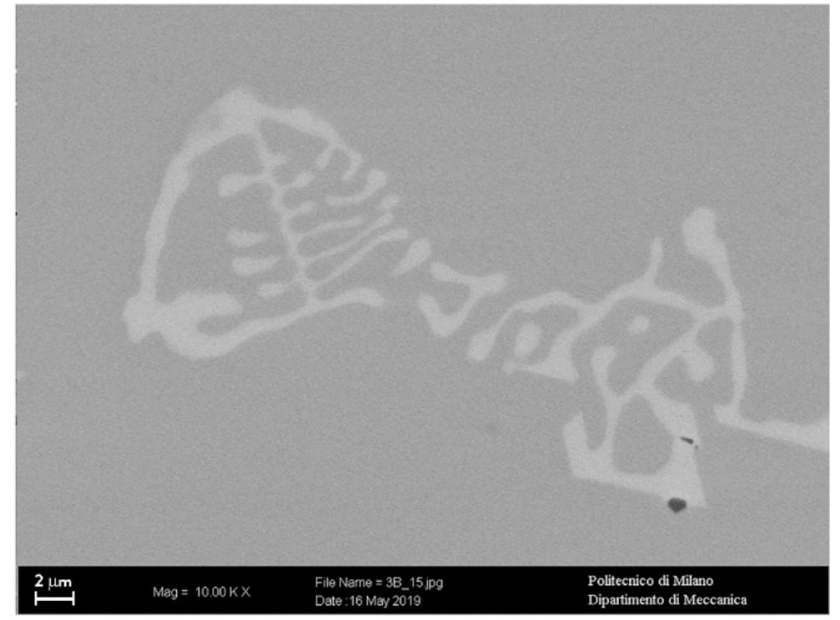

(b)

Figure 8. On the left, an overview of the secondary phases (a) in the microstructure of the ingot with a $70 \%$ amount of scrap and on the right, a detailed view of a Laves eutectic phase (b)

Table 3. Chemical Composition by SEM-EDS of the Secondary Phases of the Micrograph in Figure 7

\begin{tabular}{lllllrl}
\hline \%wt. & $\mathrm{Si}$ & $\mathrm{Cr}$ & $\mathrm{Fe}$ & $\mathrm{Ni}$ & $\mathrm{Nb}$ & $\mathrm{Mo}$ \\
\hline (A) Laves eutectic & 1.51 & 18.52 & 1.14 & 56.66 & 8.63 & 12.81 \\
(B) Laves particle & 2.69 & 15.95 & 0.96 & 42.60 & 21.61 & 16.20 \\
(C) NbC elongated & - & 1.13 & - & 2.25 & 96.62 & - \\
(D) NbC globular & - & - & - & 1.12 & 95.43 & 3.45 \\
\hline
\end{tabular}

value $\left(\mathrm{R}_{\mathrm{m}}=485 \mathrm{MPa}\right)$ prescribed by the standard ASTM $494 / 494 M^{18,19,34}$. Regarding yielding strength $\left(\mathrm{Rp}_{02}\right)$, a clear trend is not evident. Solution annealing thermal treatment does not significantly change $\mathrm{Rp}_{02}$ values. Only the sample with $100 \%$ of scrap content (full revert) fails to satisfy the limit imposed by the standard $\left(\mathrm{Rp}_{02}=275\right.$ $\mathrm{MPa}$ ). The samples have similar grain features (dimension and morphology) due to the same solidification parameters and that results in the same level of yielding ${ }^{31}$.

Solution-annealed samples exhibit higher elongation than the as-cast ones. Solution annealed ingots with $70 \%$ and $100 \%$ of scrap do not respect the elongation at break requirement $(\mathrm{A} \%=25 \%)$. The elongation reduces increasing the revert proportion: this phenomenon may be ascribed to the high-volume fraction of secondary phases, oxides and porosity which can cause inhomogeneous deformation in revert alloy ${ }^{31}$.

The fracture, after tensile tests, is mainly intergranular and propagates along the interdendrtic spaces. No cleavage was observed, and dimples were present as in high ductility alloy. The fracture surface features and morphologies are not influenced by the revert amount; samples with $70 \%$ and $100 \%$ of revert show more pores that might accelerate the crack propagation. Moreover, the crack initiation usually occurs at the interface between non-metallic inclusions and the matrix during the deformation process and since the amounts of non-metallic inclusion in revert material are higher, the mechanical properties of revert material are generally lower to those of virgin material ${ }^{31}$.

Charpy V-notch results clearly show the material's embrittlement: increasing the amount of scrap decreases the impact energy resistance. Charpy energy values for samples with a $0 \%$ and $30 \%$ scrap content show better performance, and the thermal treatment significatively improves the toughness of these samples. This behaviour can be explained by the higher amount of defects and secondary phases present in high scrap content ingots. The ingots with $70 \%$ and $100 \%$ scrap amounts are not affected by thermal treatment. Due to the higher amount of $\mathrm{C}$ and mainly $\mathrm{N}$, that nitrides and carbonitrides could not be dissolved during solution annealing and remain trapped in the matrix causing its embrittlement. ${ }^{24,27}$. The mechanical tests performed in this study on this specific alloy (CW6MC) showed that if the revert proportion is more than $30 \%$, it will slightly influence the mechanical properties of materials.

Pitting test results (Figure 13) show that $0 \%, 30 \%$ and $100 \%$ samples exhibit excellent corrosion resistance in chloride environments. The results agree with the standard requirement given for oil and gas applications (maximum 


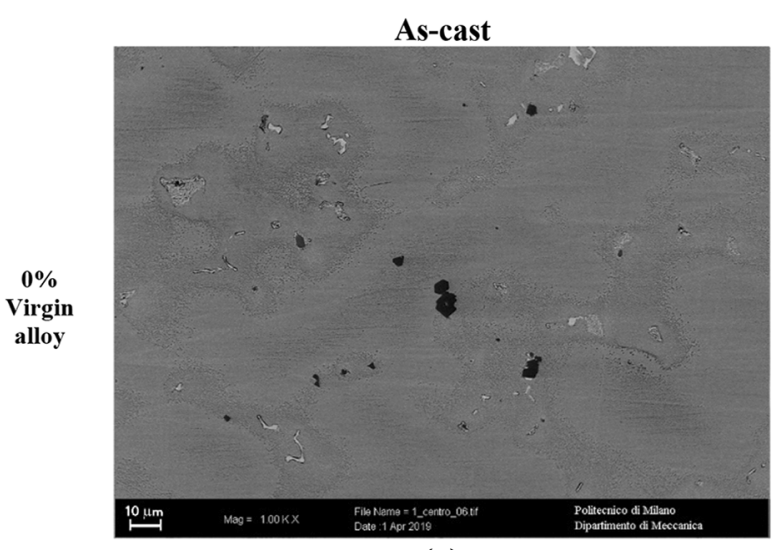

(a)

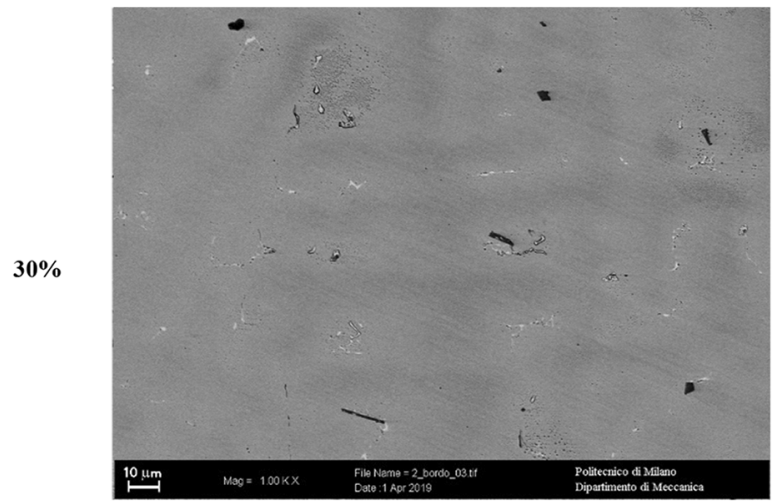

(c)

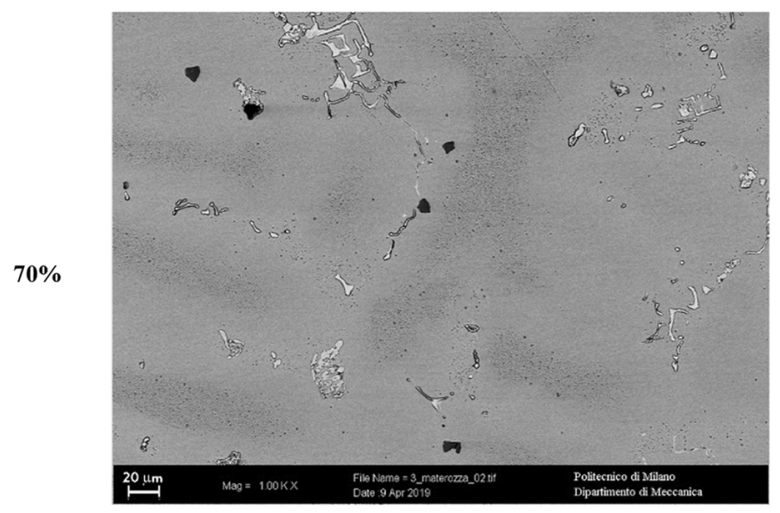

(e)

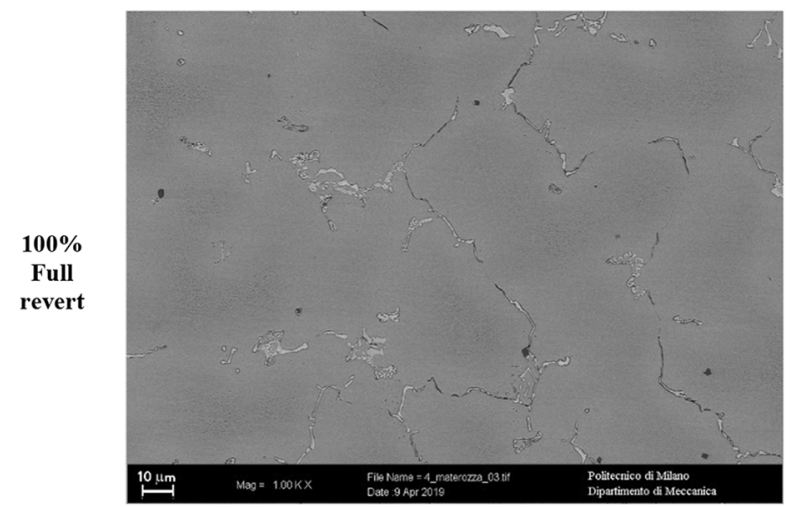

(g)

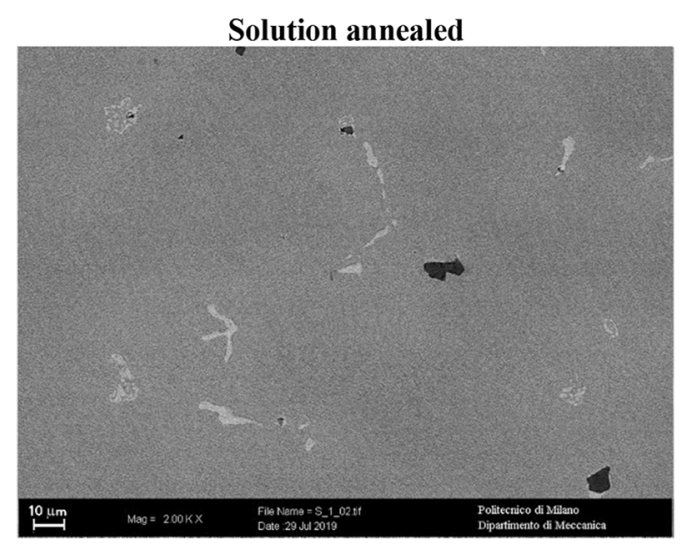

(b)

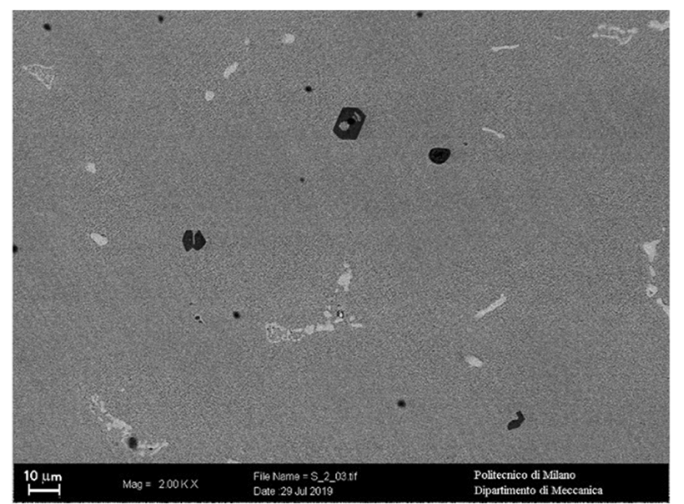

(d)

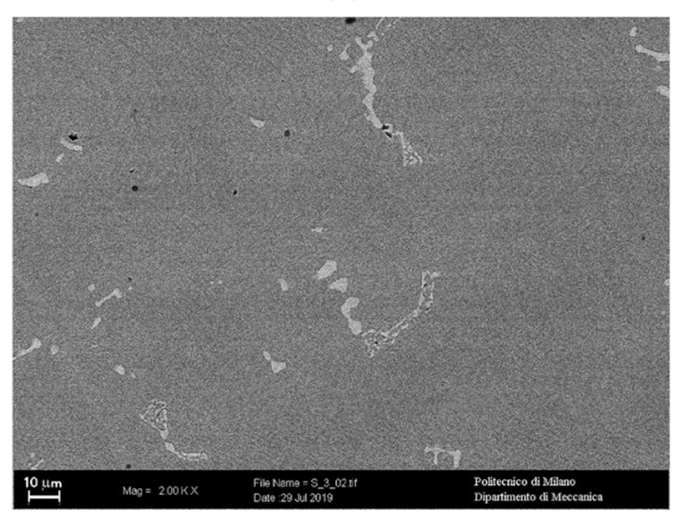

(f)

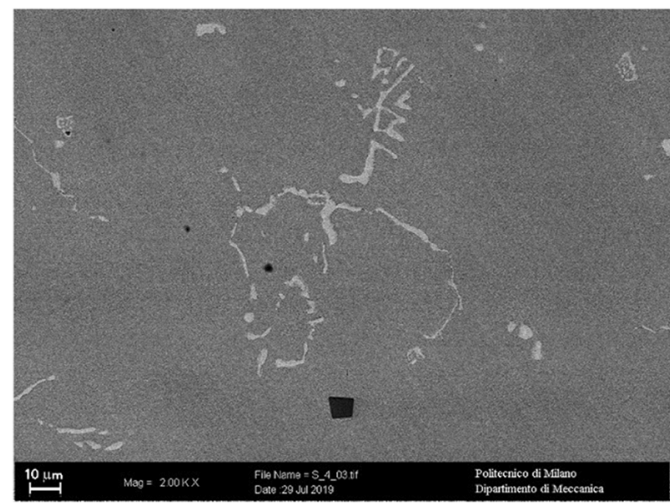

(h)

Figure 9. Different microstructure in the as-cast condition and after solubilization 


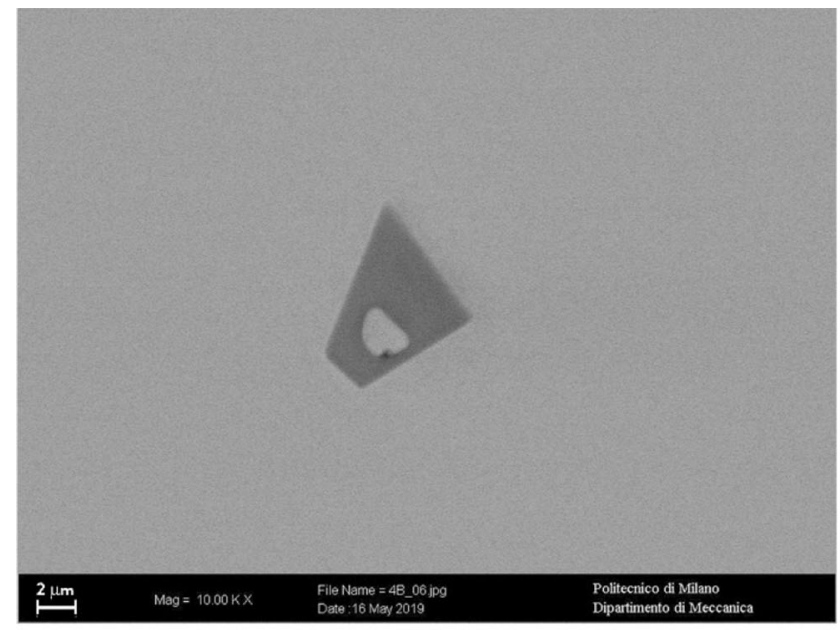

(a)

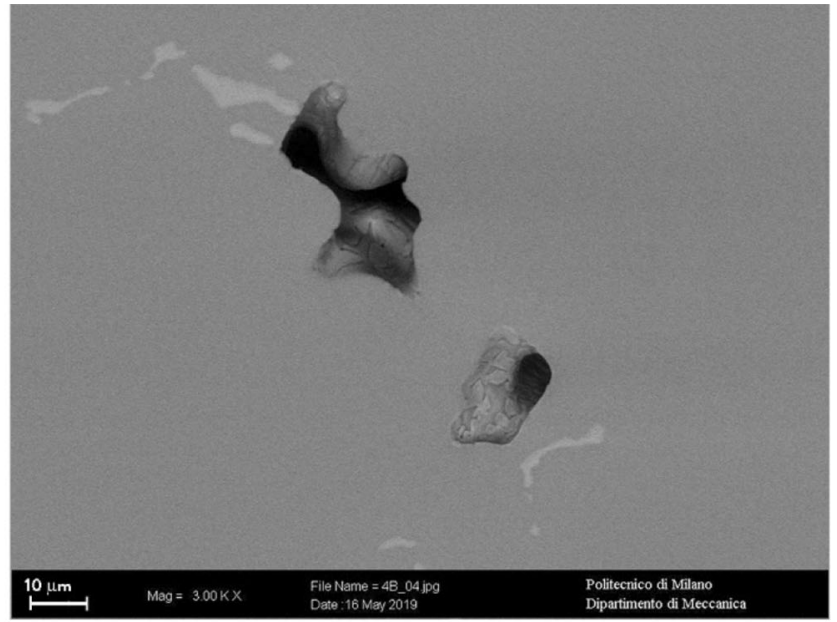

(b)

Figure 10. Cr-oxides (a) and shrinkage porosity (b) located in the interdendritic region of a $100 \%$ ingot

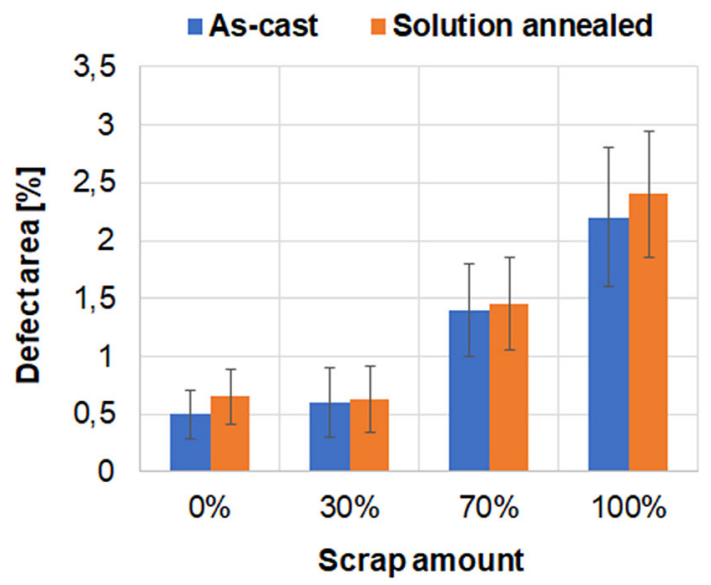

Figure 11. Trend of the defect area for different scrap amounts

allowed weight loss of $4 \mathrm{~g} / \mathrm{m}^{2}$ ). Although for these 3 samples, the weight losses are totally negligible, and the $70 \%$ sample exhibits unacceptable corrosion performance. $\mathrm{Cr}$, Mo and $\mathrm{W}$ amounts are mainly responsible for pitting resistance. Cr controls the initiation of pitting corrosion, while Mo controls the material's re-passivation ability. The weight loss trend resembles that for the Mo content. Thus, the lower Mo content is mainly responsible for the higher weight $\operatorname{loss}^{34-36}$. The fluctuation in Mo content mainly depends on the chemical composition of the charge. Since the revert has intrinsic fluctuations, the final components will also have random fluctuations. Mo content is not influenced by the foundry practice (melting loos, oxidation,...), and the chemical composition of the charge is decisive. Since we have verified that the content of Mo is independent of the amount of revert, the resistance to pitting will also be independent.

\section{Conclusion}

In this paper, the effect of internal recycling on the metallurgical features and properties of cast Ni-based alloy was investigated. It was shown that variations in the scrap content cause a substantial modification in the final chemical composition. These variations (different for each alloy element) find a simple explanation in foundry practice and strongly affect the microstructure. Indeed, as the scrap content increases, there is an increase in secondary phases (carbides, Laves and nitrites) and defects (oxides and porosity). On the other hand, the scrap content was found to not have any influence on the solidification pattern seen as grain size and morphology. This obviously involves a change in the mechanical response: mechanical properties decrease as recycling increases. No difference was detected in relation to the pitting corrosion resistance that is ruled mainly by the Mo content. In view of these results, to avoid undesirable brittleness, it is better not to exceed $30 \%$ scrap in terms of content.

The authors think that the amount of scrap that can be used may exceed the value identified by this study. This obviously depends on the plant, the equipment and the operating procedure. For example, the injection of inert gas 


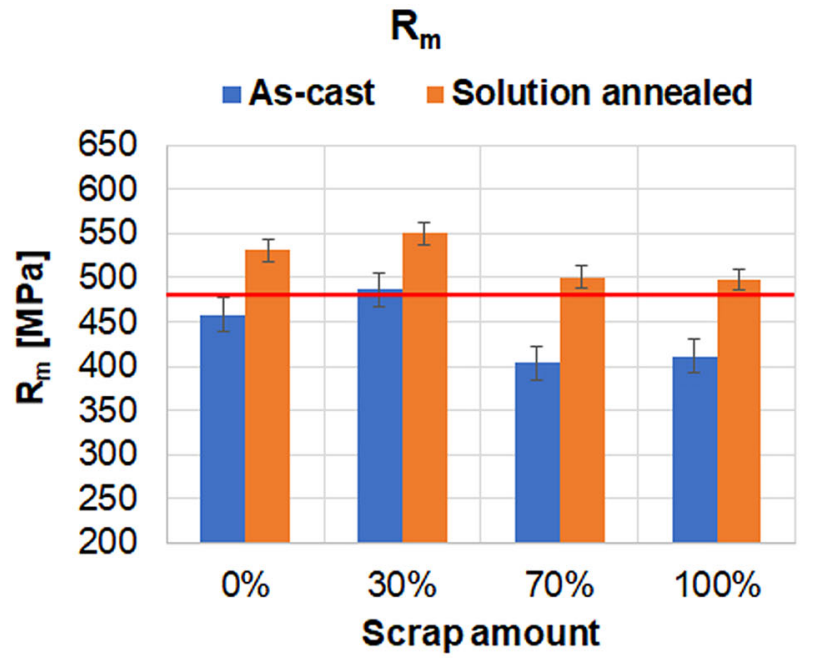

(a)

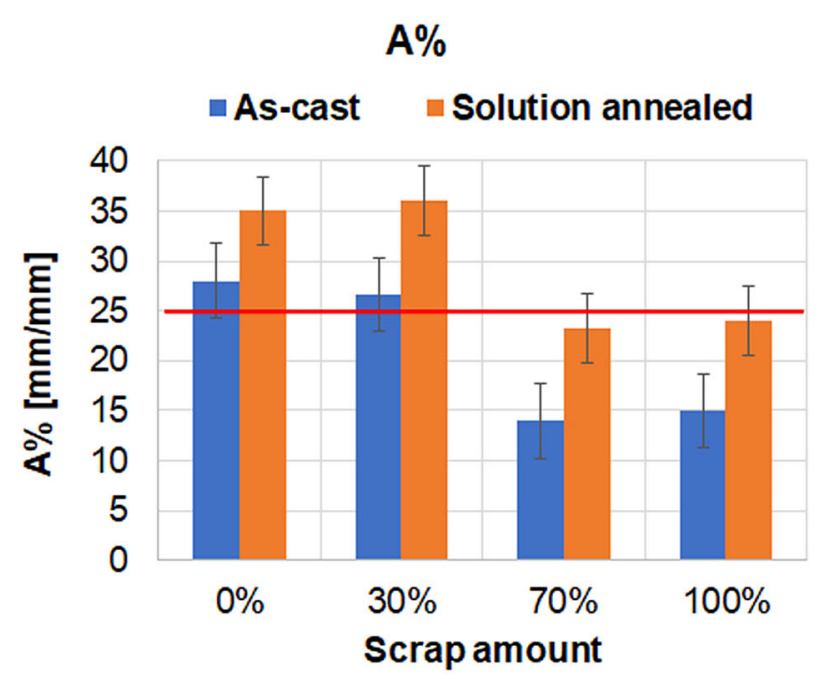

(c)

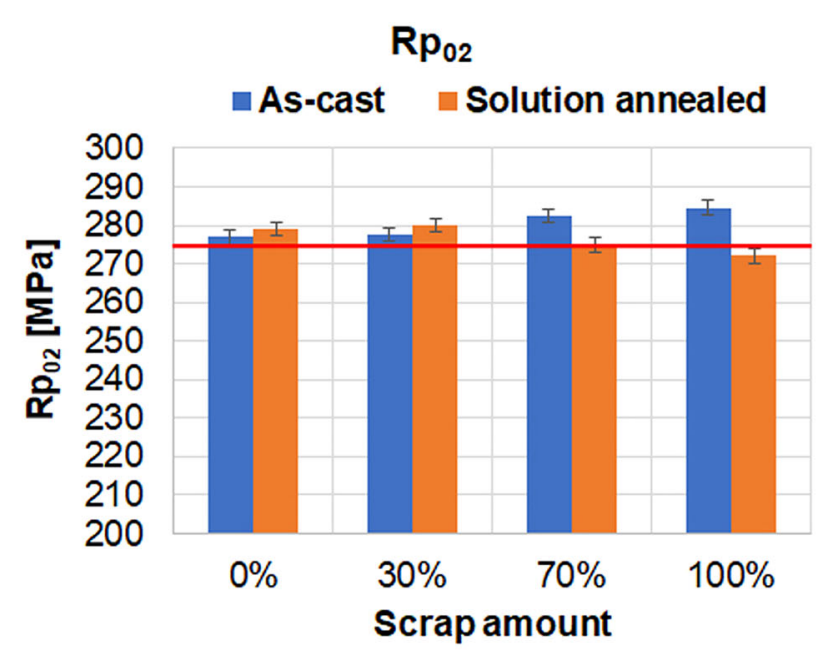

(b)

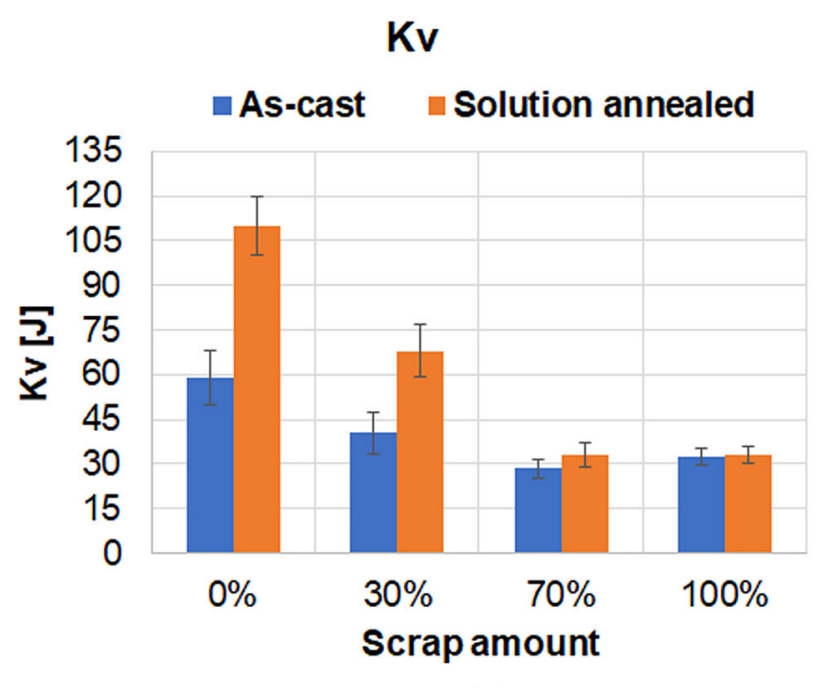

(d)

Figure 12. Mechanical response for different scrap amounts

from the furnace bottom helps to remove oxides by floating and filter during pouring and casting can reduce also the inclusions content; the protection during pouring and casting, by gas or nozzle, prevents the incorporation of atmosphere with the consequent decrease in gas porosity and brittle nitrides compounds. To reduce the secondary phases amount, it is appropriate to remain on the minimum quantities of alloying element $(\mathrm{Fe}, \mathrm{Nb}, \mathrm{Si})$ and modify the solubilization thermal treatment increase the treatment time and temperature helps in absorbing a large amount of precipitate and avoid a further formation.

In view of reducing environmental impact, saving resource, and reducing emission and not forgetting to save the cost, revert concept is fundamental in the modern industry. It can be concluded that the effect of revert addition has a negative influence on the final properties. The revert amount that is possible to charge can be increased by a 


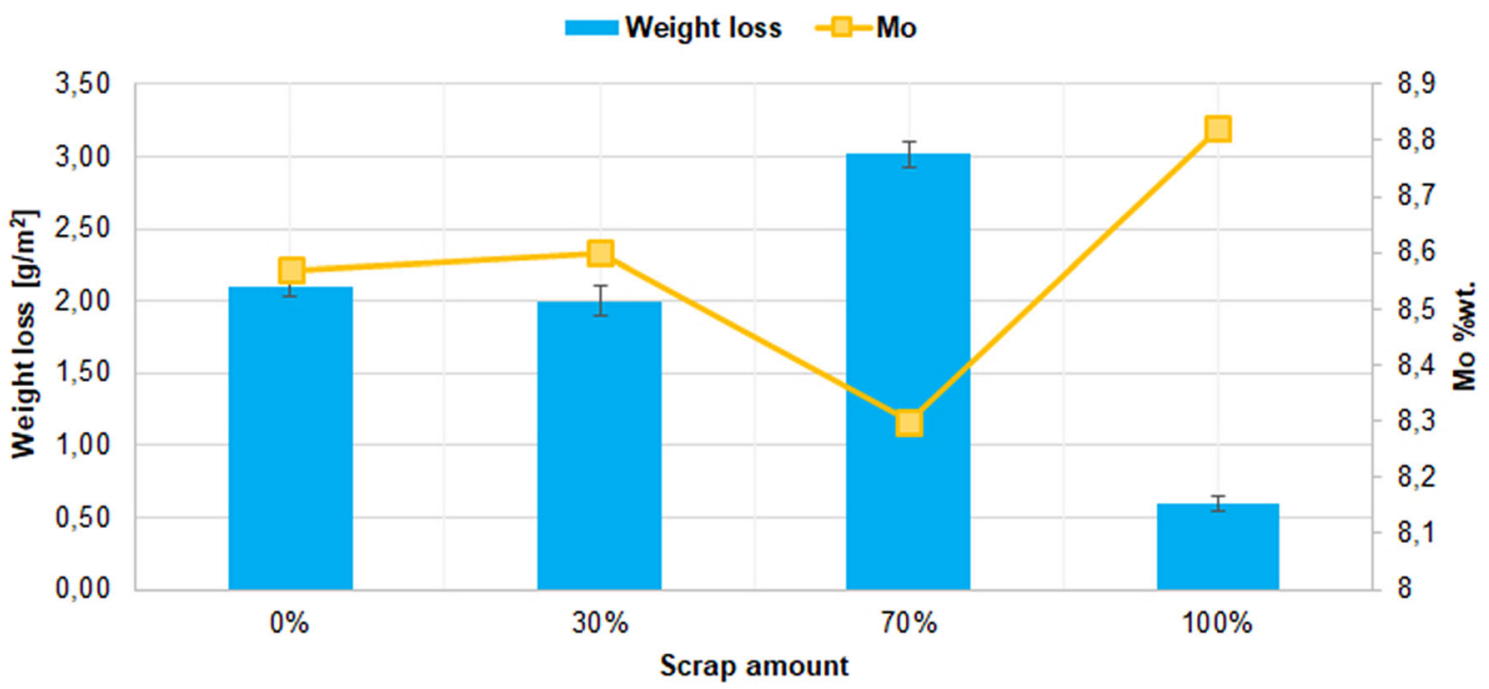

Figure 13. Corrosion pitting resistance (ASTM G48) for different scrap amounts and the corresponding Mo amount

dedicated improvement of the casting technology and process of the foundry.

\section{Acknowledgement}

The authors thank Fondinox S.p.a. for the ingots casting and for the technical support during the analysis of the results.

\begin{abstract}
Author Contributions All authors contributed to the conception and design of the study. Material preparation and data collection were done by Anna Guerra and data analysis was performed by Anna Guerra, Andrea Gruttadauria and Silvia Barella. The first draft of the manuscript was written by Anna Guerra and Andrea Gruttadauria, all authors commented on previous versions of the manuscript. All authors read and approved the final manuscript.
\end{abstract}

\section{Funding}

Open access funding provided by Politecnico di Milano within the CRUI-CARE Agreement. Not applicable.

\section{Data Availability}

Data transparency.

\section{Declarations}

Conflict of interest Not applicable.

Open Access This article is licensed under a Creative Commons Attribution 4.0 International License, which permits use, sharing, adaptation, distribution and reproduction in any medium or format, as long as you give appropriate credit to the original author(s) and the source, provide a link to the Creative Commons licence, and indicate if changes were made. The images or other third party material in this article are included in the article's Creative Commons licence, unless indicated otherwise in a credit line to the material. If material is not included in the article's Creative Commons licence and your intended use is not permitted by statutory regulation or exceeds the permitted use, you will need to obtain permission directly from the copyright holder. To view a copy of this licence, visit http://creativecommons. org/licenses/by/4.0/.

\section{REFERENCES}

1. B. Geddes, H. Leon, X. Huang, Superalloys: Alloying and Performance (ASM International, Ohio, 2010)

2. T.M. Pollock, S. Tin, J. Propuls, Power 22, 361-374 (2006)

3. J.H. Weber, M.G. Fahrman, J.R. Crum, Encycl Mater. Sci. Technol (Elsevier, Amsterdam, 2001), pp. $6135-6140$

4. M.J. Donachie, S.J. Donachie, Superalloys, 2nd edn. (ASM International, Ohio, 2002)

5. S.R. Rao, Resource Recovery and Recycling from Metallurgical Wastes, vol. 7, chap. 7 (2006), pp. $167-268$

6. A. Greenfield, T.E. Graedel, Resour. Conserv. Recycl. 74, 1-7 (2013)

7. J. Campbell, Steel Res. Int. 88, 1-13 (2017)

8. R.R. Srivastava, M.S. Kim, J.C. Lee, M.K. Jha, B.S. Kim, J. Mater. Sci. 49, 4671-4686 (2014)

9. L.R. Curwick, W.A. Petersen, J.J. DeBarbadillo, Superalloys 1980 (ASM, Materials Park, Ohio, 1980), pp. 21-30

10. R. Cygan, P. Zywicki, T. Szczech, M. Kwiatkowski, 72nd World Foundry Congr. WFC 2016, 225-226 (2016)

11. ASTM A494/A494M-18a, Standard Specification for Castings (Nickel and Nickel Alloy, ASTM International, West Conshohocken, PA, 2018)

12. G.F. Vander Voort, Metallography Principles and Practice (ASM International, Ohio, 1999)

13. ASTM E-407 Standard Practice for Microetching Metals and Alloys (ASTM International, West Conshohocken, PA, 2016) 
14. ASTM E8/E8M Standard Test Methods for Tension Testing of Metallic Materials 1 (ASTM International, West Conshohocken, PA, 2010)

15. ASTM E23 Standard Test Methods for Notched Bar Impact Testing of Metallic Materials (ASTM International, West Conshohocken, PA, 2018)

16. ASTM G48-11, Standard Test Methods for Pitting and Crevice Corrosion Resistance of Stainless Steels and Related Alloys by Use of Ferric Chloride Solution (ASTM International, West Conshohocken, PA, 2015)

17. C. Yuan, J. Guo, C. Liu, J. Hou, G. Li, Mater. Sci. Forum 747-748, 715-722 (2013)

18 M.J. Cieslak, T.J. Headley, T. Kollie, A.D. Romig, Metall. Trans. A Phys. Metall. Mater. Sci. 19, 2319-2331 (1988)

19. S. Floreen, G.E. Fuchs, W.J. Yang, Superalloys 718, 13-37 (1994)

20. N. El-bagoury, Int. J. Eng. Sci. Res. Technol. 5, 108-152 (2016)

21 J.N. Dupont, Metall. Mater. Trans. A Phys. Metall. Mater. Sci. 27, 3612-3620 (1996)

22. S. Barella, A. Gruttadauria, C. Mapelli, D. Mombelli, T. Paolo, B. Matteo, M. Alberto, China Foundry 14, 304-312 (2017)

23. J. Hou, F. Yang, Y. Wu, L. Zhou, J. Alloys Compd. 785, 1038-1046 (2019)

24. C. Fuwang, H. Xuebing, Z. Yun, L. Yulin, H. Zhuangqi, Mater. High Temp. 14, 421-424 (1997)

25 T.J. Garosshen, T.D. Tillman, G.P. McCarthy, Metall. Trans. A Phys. Metall. Mater. Sci. 18, 69-77 (1987)
26 X. Huang, Y. Zhang, Y. Liu, Z. Hu, Metall. Mater. Trans. A Phys. Metall. Mater. Sci. 28, 2143-2147 (1997)

27. X.L. Guo, J.B. Yu, X.F. Li, Y. Hou, Z.M. Ren, Ironmak. Steelmak. 45, 215-223 (2018)

28. Y.Z. Zhou, A. Volek, Scr. Mater. 56, 537-540 (2007)

29. J. Tinoco, H. Fredriksson, High Temp. Mater. Process. 23, 13-24 (2004)

30. G.L.R. Durber, S. Osgerby, P.N. Quested, Met. Technol. 11, 129-137 (1984)

31. Y.H. Yang, J.J. Yu, X.F. Sun, T. Jin, H.R. Guan, Z.Q. $\mathrm{Hu}$, Mater. Sci. Eng. A 532, 6-12 (2012)

32. J. Campbell, Complete Casting Handbook: Metal Casting Processes, Metallurgy (Second Edition, Techniques and Design, 2015)

33. A. Gruttadauria, S. Barella, C. Fiocchi, Mechanical response of Ni-based CU5MCuC alloy to different stabilization thermal treatments. Inter Metalcast (2020). https://doi.org/10.1007/s40962-020-00519-x

34. C.A.C. Sequeira, D.S.P. Cardoso, L. Amaral, B. Šljukić, D.M.F. Santos, Corros. Rev. 34, 187-200 (2016)

35. I. Forest, P.O.B. Suffern, Int (Inc, Nickel Company, 1983), pp. 1-88

36 H.S. Klapper, N.S. Zadorozne, R.B. Rebak, Acta Metall. Sin. English Lett. 30, 296-305 (2017)

Publisher's Note Springer Nature remains neutral with regard to jurisdictional claims in published maps and institutional affiliations. 